\title{
KUKKAKAALIN VARASTOINNISTA
}

\author{
IRMA SUHONEN \\ Helsingin yliopiston puutarhatieteen laitos, Viik
}

Saapunut 10.12. 1966

Viimeisempien tilastotietojen mukaan kukkakaalia viljellään maassamme vuosittain noin 150 hehtaarin alalla, josta myyntituottoisten viljelmien osuus on noin 100 ha. Keskimääräisen hehtaarisadon mukaan tämä merkitsee yli miljoonan kilon vuotuista tuotantoa. Lisäksi tuodaan maahamme vuodessa 0.6 miljoonaa kiloa (keskiarvo vuosilta 1961—65) kukkakaalia. Koska kukkakaali ei siedä pitkäaikaista varastointia, markkinoidaan kotimaassa tuotettu kukkakaali kesä- ja lokakuun välisenä aikana. Tämä merkitsee sitä, että maassamme vuosittain tuoreena markkinoidusta kukkakaalista 2/3 markkinoidaan neljän viiden kuukauden aikana. Tällöin viljelijäin kukkakaalista saama hinta on epävakaa, mikä johtuu siitä, että tuoteruuhkia syntyy helposti. Tilannetta pahentaa se, että kukkakaalin kehitysnopeus vaihtelee sääolojen mukaan. Luonteenomaista on, että lämpimän kauden jälkeen markkinoilla on kukkakaalia niin runsaasti, että sen hinta laskee. Hintojen epävakaisuutta voitaisiin korjata ajoittamalla tuotantoalueittain viljelyä sekä poistamalla liikaeriä markkinoilta pakastamista käyttäen.

Kukkakaalin viimeaikaisissa hinnan vaihteluissa ilmenee, että esimerkiksi heinäkuussa aikaisen sadon valmistuessa tuoteruuhkien aiheuttama alhainen hinta on väliaikainen ilmiö, joka kestää $2-3$ viikkoa. Tämän jälkeen hinta tarjonnan niukkuuden takia saattaa nousta huomattavasti. Samankaltaista hinnan epävakaisuutta esiintyy myös satokauden lopulla, joskaan vaihtelu ei ole niin suurta kuin heinäkuussa. Koska on ilmeistä, että varsinaisena satokautenakin on joskus puutetta kukkakaalista, on syytä selvittää, olisiko mahdollista varastoida ruuhkautuneita kukkakaalieriä, kuinka pitkään kukkakaalin varastointia äärimmäistapauksessa voidaan jatkaa ja minkälaisia tappioita varastoinnin aikana koituu.

Edellä esitettyihin näkökohtiin perustuen ja koska kirjallisuustiedot aiheesta olivat varsin niukat, ryhdyttiin Helsingin yliopiston puutarhatieteen laitoksella v. 1963 selvittämään kukkakaalin varastoimismahdollisuuksia sekä varastoinnin aikana tapahtuvia paino- ja laatutappioita.

Aikaisemmista tutkimuksista ja kirjallisuustiedoista käy ilmi, että kukkakaali säilyy parhaiten $-1-+1^{\circ} \mathrm{C}$ lämpötilassa ilman suhteellisen kosteuden ollessa 
90-95\% (PIEH 1965, RosE et al. 1949). Näissä oloissa sen mainitaan säilyvän $2-3$ viikkoa. Viime aikoina kukkakaalin varastointia on tutkittu USA:ssa, Saksassa, Hollannissa, Ruotsissa ja Suomessa. Tutkimukset ovat kohdistuneet varastoinnin aikana tapahtuvaan erilaisten kelmujen käyttöön (BANHOLzER 1965, FRIEdRICH et al. 1963, KARCH 1965, Kurki 1966, Åvall 1957), lehtien irtoamiseen (Hruschka et al. 1949, KAUfman et al. 1961, LEE et al. 1949), valon aiheuttamaan kukinnon pinnan tummumiseen (BROUWER et al. 1955) ja ennen varastointia suoritettaviin esikäsittelyihin (VoIPIO 1966).

\section{Aineisto ja menetelmät}

Tutkimuksiin tarvittava kukkakaaliaineisto (lajike Flora Blanca) kasvatettiin Puutarhatieteen laitoksen koekentällä Viikissä. Kukkakaalien taimet kasvatettiin lavassa, eikä taimia koulittu. Taimet istutettiin avomaalle kesäkuun puolivälin jälkeen (taulukko 1). Peruslannoituksena annettiin puutarhan Y-lannosta $10 \mathrm{~kg} / \mathrm{aja}$ ennen istutusta taimien juuret käsiteltiin möhöjuuren ja kaalikärpäsen torjumiseksi CRC-tehostettu-nimisellä valmisteella. Istutusetäisyys oli $50 \times 60 \mathrm{~cm}$. Kasvukauden aikana torjuttiin tuholaisia Bladan E 605, Roxion ja Malasiini-nimisillä valmisteilla.

Taulukko 1. Kukkakaalin kylvö-, istutus- ja sadonkorjuuajat.

Table 1. Sowing, planting and harvesting time of cauliflower.

$\begin{array}{cccc}\begin{array}{c}\text { Vuosi } \\ \text { Year }\end{array} & \begin{array}{c}\text { Kylvö } \\ \text { Sowing }\end{array} & \begin{array}{c}\text { Istutus avomaalle } \\ \text { Planting }\end{array} & \begin{array}{c}\text { Sadonkorjuu alkaa } \\ \text { Harvesting starts }\end{array} \\ 1963 . & 28.5 . & 25.6 . & 15.8 . \\ 1964 . & 26.5 . & 17.6 . & 22.8 . \\ 1965 . & 26.5 . & 28.6 . & 14.9 . \\ 1966 . & 21.5 . & 23.6 . & 23.8 .\end{array}$

Sadonkorjuu aloitettiin silloin, kun kukinnot olivat saavuttaneet korjuukypsyyden, mikä tapahtui elokuun puolivälissä. Viileän kesän takia kukkakaali valmistui v. 1965 vasta syyskuussa (taulukko 1).

Korjuun jälkeen I-lajitelmaa vastaavat kukinnot (vrt. Vihanneksien, marjojen ja omenien lajittelu- ja pakkausohjeet 1963) kunnostettiin varastointia varten. Suojuslehdet typistettiin niin, että noin $10 \mathrm{~cm}$ niiden kannasta jäi suojaamaan kukintoa. Kunnostuksen jälkeen varastoitavat erät punnittiin ja pakattiin puulaatikoihin yhdeksi kerrokseksi. Pakkaukseen käytetty PV-muovi leikattiin $1 \mathrm{~m}: \mathrm{n}$ pituisiksi ja $30 \mathrm{~cm}$ levyisiksi pusseiksi ja niihin tehtiin $16 \mathrm{kpl}$ halkaisijaltaan $5 \mathrm{~mm}: \mathrm{n}$ suuruisia pyöreitä reikiä. Kokeissa kukin koejäsen käsitti 5 kerrannetta, kussakin 5 kukintoa.

Heti kunnostuksen ja pakkauksen jälkeen erät vietiin koekellariin, jossa ilman lämpötila oli $1-2^{\circ}$ ja suhteellinen kosteus $90-95 \%$. Määräajoin varastoinnin kestäessä sekä sen jälkeen kukkakaalit punnittiin ja arvosteltiin. Punnitustulokset ilmaistaan seuraavassa prosentteina alkuperäisestä painosta. Kukkakaalin laadun arvostelu tapahtui seuraavasti: 
I. Kukinto arvosteltiin numeroilla 3-0, jolloin

$3=$ virheetön

$2=$ pisteitä kukinnon pinnassa

1 = laikkuja (

$0=$ yli puolet kukinnon pinnasta vioittunut

II. Lehdet arvosteltiin numeroilla $3-0$, jolloin

$\mathbf{3}=$ lehdet vihreät

2 = lehdet harmaanvihreät tai kellertävät

$1=$ lehdet ruskeanvihreät tai keltaiset

$0=$ lehdet mädäntyneet

III. Kukinnon kovuus arvosteltiin käsin koettelemalla joko »kovaksi» tai »pehmeäksi» ja kovuutta kuvataan asteikolla $100-0$, jolloin $100=$ kaikki kukinnot kovia ja $0=$ kaikki kukinnot pehmeitä.

\section{Tulokset}

Vuonna 1963 kukkakaalia varastoitiin 4:n, 6:n ja 10:n viikon pituiset jaksot. Tulokset tästä kokeesta olivat seuraavat:

Paino ( $\%$ alkuperäisestä) varastoinnin jatkuttua

\begin{tabular}{|c|c|c|}
\hline $28 \mathrm{vrk}$ & 42 vrk & $70 \mathrm{vrk}$ \\
\hline $86 \%$ & $78 \%$ & $67 \%$ \\
\hline
\end{tabular}

Neljä viikkoa kestäneen varastoinnin aikana kukinnot olivat menettäneet $14 \%$ painostaan, ja vaikka pintavioituksia oli vain vähän, olivat erät nahistumisen takia kauppaan kelpaamattomia. Koska oli ilmeistä, että koekellarissa vallitsevissa oloissa nahistuminen aiheutti eniten kauppa-arvon alenemista, keskityttiin seuraavina vuosina selvittämään haihdunnan määrää sekä muovipakkauksen merkitystä siinä.

Tulokset v. 1964 suoritetuista kokeista esitetään taulukossa 2. Kokeessa I tutkittiin muovipakkauksen vaikutusta haihduntaan. Tällöin todettiin, että kuusi viikkoa kestäneen säilytyksen jälkeen muovissa säilytettyjen erien haihtumistappio oli $1 \%$ ja ilman muovia säilytettyjen $23 \%$. Muovissa olleiden kukintojen lehdet olivat kauniin vihreät, mutta kukintojen pinnassa oli runsaasti pistemäisiä painaumia. Kokeessa II tutkittiin erisuuruisista kukinnoista tapahtuvaa haihduntaa, ja tällöin todettiin, että keskikokoiset $(0.65 \mathrm{~kg})$ kukinnot haihduttivat vähiten. Ero muihin kokoihin nähden (taulukko 2 ) oli tilastollisesti merkitsevä vasta 7 viikkoa kestäneen varastoinnin jälkeen, jolloin parhaitenkin säilynyt lajitelma, keskikokoiset, oli pintavioitusten ja nahistuneisuuden takia kauppaan kelpaamatonta. Haihtumistappio oli kaikissa koejäsenissä 14 vrk kestäneen varastoinnin jälkeen keskimäärin $9 \%$ ja 28 vrk kestäneen varastoinnin jälkeen keskimäärin $17 \%$.

Vuonna 1965 toistettiin kokeet kukinnon koon ja muovin merkityksestä. Tällöin todettiin (taulukko 3), että keskikokoiset kukinnot säilyivät hieman paremmin kuin suuret tai pienet. Keskikokoisten kukintojen haihtumishäviö oli ensimmäisen varastointiviikon aikana $4.6 \%$, toisen $2.8 \%$, kolmannen $4.2 \%$ ja neljän- 
Taulukko 2. Kukkakaalin varastointi v. 1964.

Table 2. Experiments on storing cauliflower in 1964.

Koe Experiment I

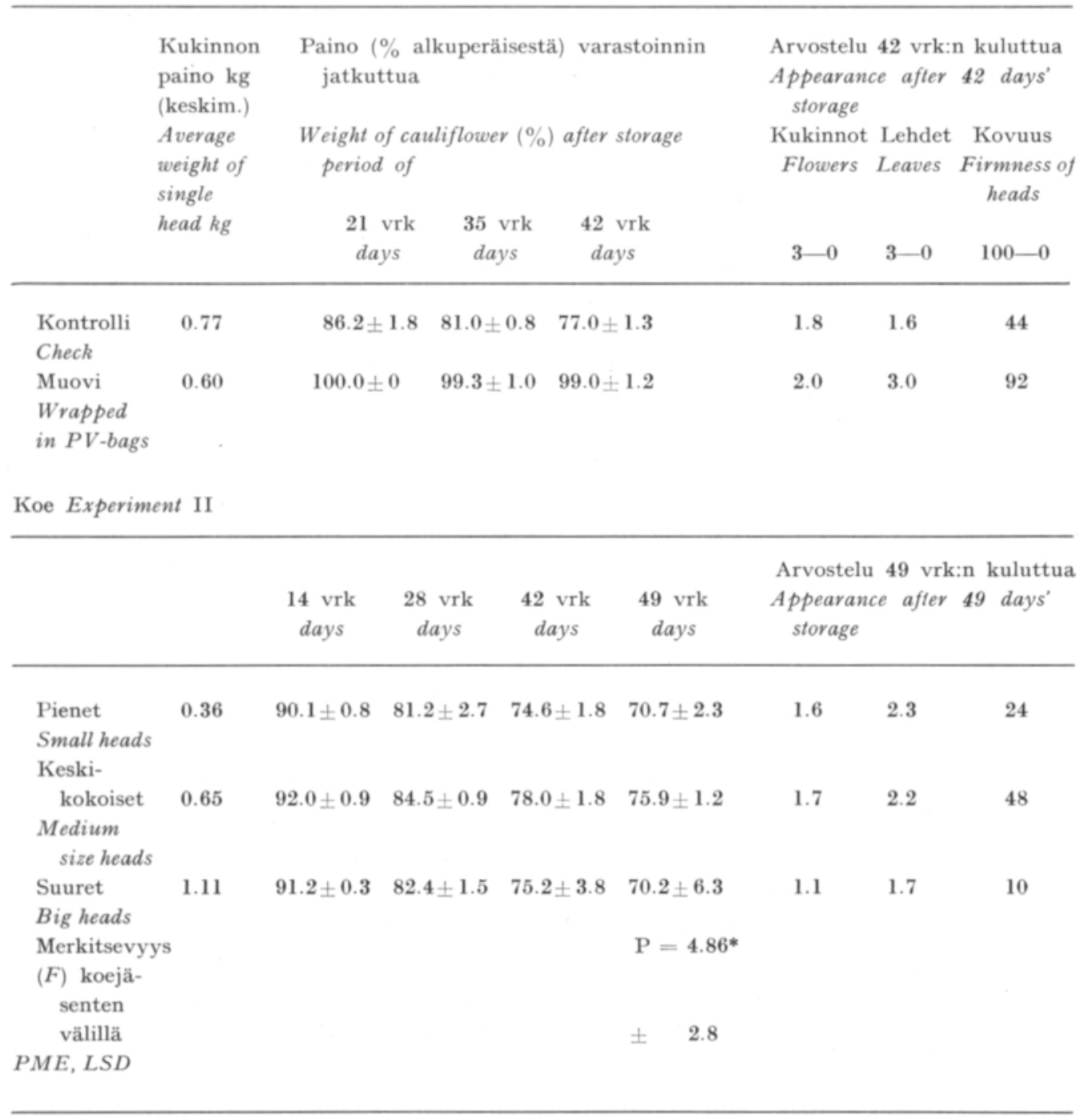

nen varastointiviikon aikana $1.8 \%$. Kookkaimmat kukkakaalit menettivät neljän ensimmäisen varastointiviikon aikana $0.4-1.0 \%$ vähemmän painostaan kuin keskikokoiset, mutta tilastollista merkitsevyyttä ei eri kokolajitelmien välisissä haihtumistappioissa todettu. Kokeessa kaikki erät säilyivät kauppakelpoisina kaksi viikkoa, kolmannen varastointiviikon jälkeen esiintyi ilman muovia säilytetyissä erissä siinä määrin pehmenneitä kukintoja (kovuus 72), että ne olisivat vaatineet lajittelun ennen markkinointia. Muoviin pakattujen kukintojen kovuus oli vielä tällöin 100 ja niiden ulkonäkö virheetön. Neljännen varastointiviikon jälkeen havaittiin kukinnoissa pintavioituksia, muovissa vähiten. Viidennen varastointi- 
viikon jälkeen olivat muoviinkin pakatut erät pintavioitusten takia kauppaan kelpaamattomia.

Taulukko 3. Kukkakaalin varastointi v. 1965.

Table 3. Experiment on storing cauliflower in 1965.

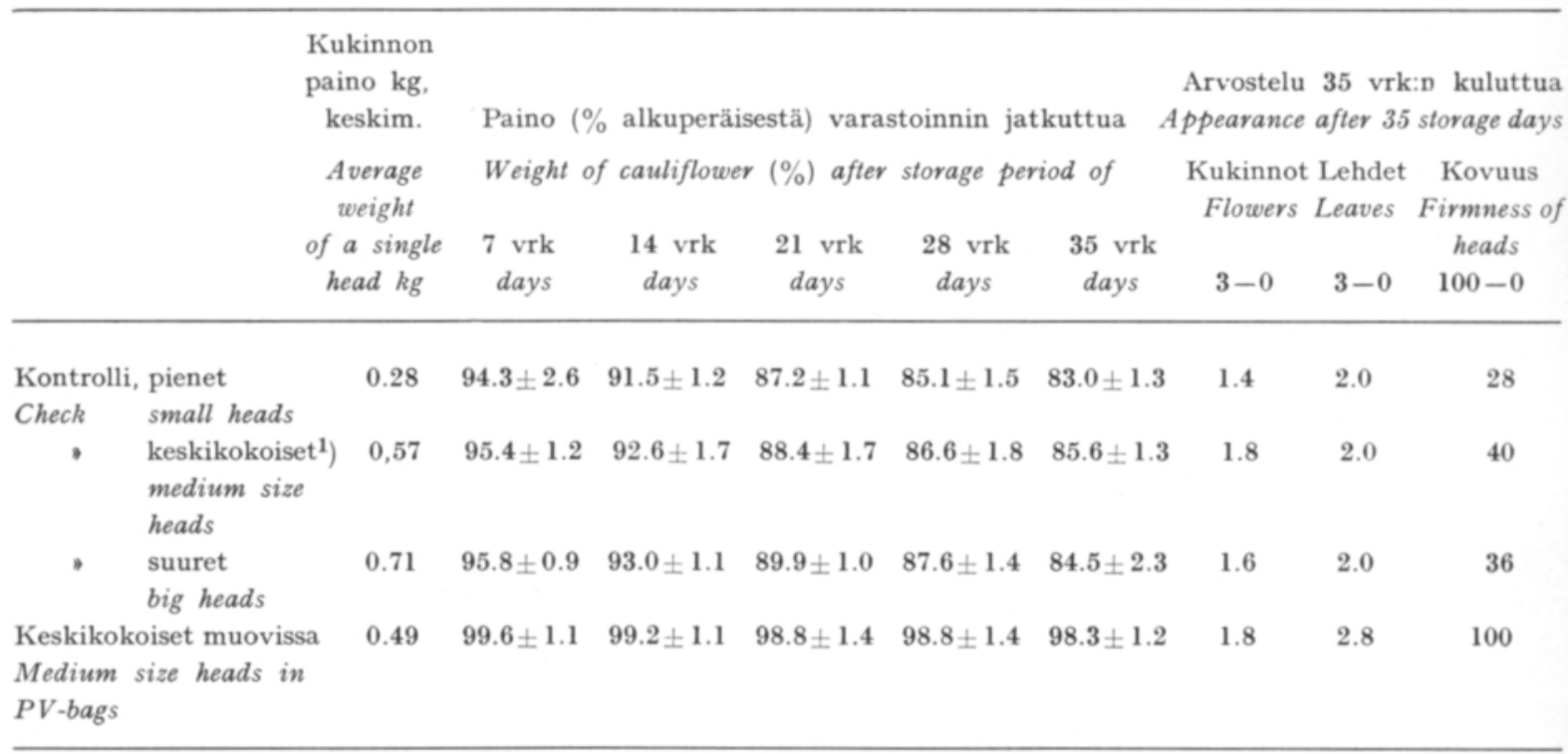

1) Koejäsen ollut vertailueränä esikäsittelykokeissa (vrt. VoIPıo 1966)

Vuoden 1966 varastointikokeissa selvitettiin tarkemmin viikoittain tapahtuvaa lehtien ja kukintojen vioittumista sekä kukintojen pehmenemistä. Tulokset esitetään taulukossa 4, ja niistä nähdään, että kukinnot saivat pintavioituksia kontrollierässä sekä muoviin pakatussa erässä samalla tavoin. Muovissa sen sijaan lehdet säilyivät jokseenkin virheettöminä ja kukinnot kovina. Kontrollierässä oli haihtumistappio ensimmäisen varastointiviikon aikana $4.2 \%$, toisen viikon aikana $2.6 \%$, kolmannen viikon aikana $2.8 \%$ ja neljännen viikon aikana $1.1 \%$. Muoviin pakattujen erien haihtumistappio oli neljä viikkoa jatkuneen säilytyksen jälkeen $1.3 \%$.

\section{Tulosten tarkastelu}

Kukkakaalin varastoinnin hankaluus ilmenee siinä, että sadonkorjuun ja käsittelyn yhteydessä on vaikeaa silmävaraisesti arvioida, mitkä kukinnot sietävät varastoinnin. Vaikka nyt selostetuissa kokeissa varastoitiin vain parhaimmat kaalit, kävi ilmi, että toiset yksilöt pehmenivät nopeasti ja tulivat "harvan» näköisiksi, mutta toiset pysyivät kiinteinä pitkän ajan. Kokeissa v. 1965 ja 1966 esimerkiksi havaittiin, että kolmen viikon varastoinnin aikana $1 / 4$ kukinnoista pehmeni, mikä ensinnä aiheutti varastoitujen erien kauppa-arvon alenemista. Eräissä tutkimuksissa cn päädytty siihen käsitykseen, että pienet kukinnot säilyvät paremmin kuin suu- 
Taulukko 4. Kukkakaalin varastointi v. 1966. Kukinnon paino keskimäärin 0.64 kg.

Table 4. Experiment on storing cauliflower in 1966. Average weight of heads $0.64 \mathrm{~kg}$.

\begin{tabular}{|c|c|c|c|c|c|c|}
\hline & & & & $\begin{array}{l}\text { Varastoi } \\
\text { Length }\end{array}$ & $\begin{array}{l}\text { in pituus } \\
\text { storage }\end{array}$ & \\
\hline & & & $\begin{array}{c}7 \text { vrk } \\
\text { days }\end{array}$ & $\begin{array}{l}14 \text { vrk } \\
\text { days }\end{array}$ & $\begin{array}{l}21 \text { vrk } \\
\text { days }\end{array}$ & $\begin{array}{l}28 \text { vrk } \\
\text { days }\end{array}$ \\
\hline \multirow{8}{*}{$\begin{array}{l}\text { Kontrolli, } \\
\text { Check }\end{array}$} & haihtumistappio & $\%$ & 4.2 & 6.8 & 9.6 & 10.7 \\
\hline & evaporation losses & $\%$ & & & & \\
\hline & kukinnon arvostelu & $3-0$ & 3.0 & 2.8 & 2.3 & 2.2 \\
\hline & appearance of flowers & $3-0$ & & & & \\
\hline & lehtien arvostelu & $3-0$ & 3.0 & 2.9 & 2.2 & 2.0 \\
\hline & appearance of leaves & $3-0$ & & & & \\
\hline & kovuuden arvostelu & $100-0$ & 100 & 84 & 76 & 56 \\
\hline & firmness of heads & $3-0$ & & & & \\
\hline \multirow{8}{*}{$\begin{array}{l}\text { Muovi, } \\
\text { Wrapped } \\
\text { in PV-bags }\end{array}$} & haihtumistappio & $\%$ & 0.4 & 1.1 & 1.1 & 1.3 \\
\hline & evaporation losses & $\%$ & & & & \\
\hline & kukinnon arvostelu & $3-0$ & 3.0 & 2.8 & 2.4 & 2.0 \\
\hline & appearance of flowers & $3-0$ & & & & \\
\hline & lehtien arvostelu & $3-0$ & 3.0 & 3.0 & 3.0 & 2.8 \\
\hline & appearance of leaves & $3-0$ & & & & \\
\hline & kovuuden arvostelu & $100-0$ & 100 & 100 & 100 & 100 \\
\hline & firmness of heads & $100-0$ & & & & \\
\hline
\end{tabular}

ret (HruschKa et al. 1949. KRUYK 1957). APELANd (1958) pitää mahdollisena syynä tähän sitä, että pienet kukinnot ovat kiinteämpiä kuin suuret. Vaikka Viikissä suoritetuissa kokeissa ei eri kokojen välisiä merkitseviä haihtumiseroja todettu, säilyivät keskikokoiset 500 - 600 g:n painoiset kukinnot selvästi kauimmin »kovina». Suurien kukintojen keskikokoisiin verrattuna heikompaa säilyvyyttä voitaneen selittää siten, että ne moitteettomasta ulkonäöstään huolimatta ovat ylikypsiä. Pienimmät kukinnot haihduttivat eniten. Tämä saattaa johtua siitä, että niillä on tilavuuteen nähden suhteellisen runsaasti haihduttavaa pintaa.

Keskikokoisen kukkakaalin haihtumistappio oli v. 1964-66 kahden viikon säilytyksen jälkeen keskimäärin $7.4 \%(6.8-8.0)$ ja varastoinnin kestettyä neljä viikkoa keskimäärin $13.2 \%(10.7-15.5)$. Haihtumistappio oli pienentynyt viimeisinä tutkimusvuosina. Tämä johtui siitä, että koekellarissa lämpötila oli v. 1963 ja 1964 enimmäkseen $2^{\circ}$ ja suht. kost. $90 \%$. V. 1964 ja 1965 lämpötila oli enimmäkseen $1^{\circ}$ ja suht. kost. $95 \%$. Haihtuminen oli suurinta ensimmäisen varastointiviikon aikana, toisen varastointiviikon aikana se pieneni. Kolmannen varastointiviikon aikana haihdunnan määrä hieman suureni ja neljännen varastointiviikon aikana tuntuvasti väheni. Kuvassa 1 esitetään yhteenveto v. 1965 ja 1966 todetuista painotappioista. Yhdistämällä eri viikkojen haihdunnan määrät saadaan loiva S-käyrä. Tästä kuvastuu, kuinka kukkakaalin elintoiminnat varastoinnin alussa olivat vilkkaat ja kuinka ne hiljenivät, kunnes kolmannen varastointiviikon aikana haihduntakäyrän lievä nousu ennakoi pilaantumista, lähinnä kukinnon pinnan vioittumista. 


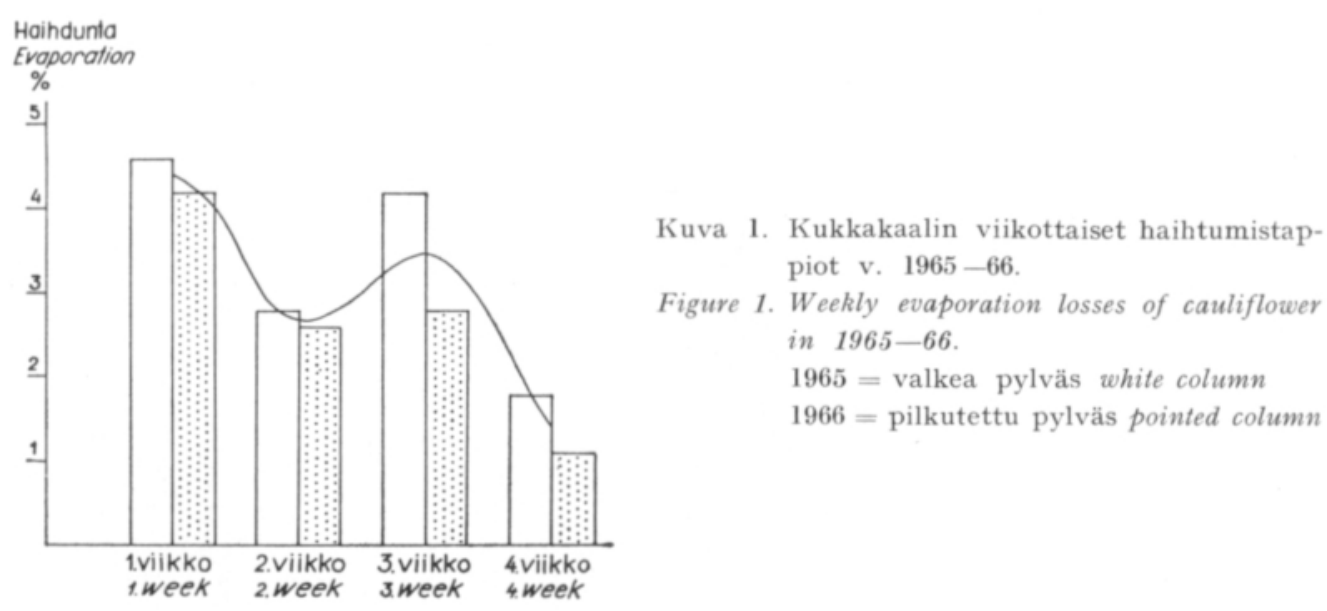

Koe-eriä arvosteltaessa havaittiin, että kukintojen pintavioituksia alkoi esiintyä runsaasti kolmannen ja varsinkin neljännen varastointiviikon aikana. Kukinnoissa esiintyi pääasiassa kahdenlaista vioitusta. Ensiksi ilmaantui kukintojen pintaan "pisteitä", jotka aiheutuivat yksityisten kukka-aiheiden kuolemisesta. Kun varastointia tästä jatkettiin, ilmaantui kukinnon pintaan laikkuja, joista eristettiin mm. Botrytis-, Fusarium- ja Penicillium-sieniä. Jos varastointia jatkettiin vain kuukauden verran, ei silmin havaittavaa sienisaastuntaa todettu.

Kukkakaalin lehtien ulkonäkö kärsi ensin nahistumisesta, ne menettivät kirkkaan värinsä. Lehtien kellastumista ja ruskettumista esiintyi vasta sitten, kun kukinnot muutenkin olivat kauppaan kelpaamattomia. Kukkakaalin lehtien irtoamista ei Viikin koekellarissa havaittu. Onkin ilmeistä, että tätä esiintyy vasta, jos varaston ilman lämpötila on korkeampi ja suhteellinen kosteus alhaisempi (KAUFMAN et al. 1961, LEE et al. 1949) kuin Viikin kokeissa.

Eräissä tutkimuksissa on myös selvitetty sitä, kuinka paljon kukkakaalin lehtiä on poistettava ennen varastoon panoa (BANHolzer 1965, Gröschner 1963, Åvall 1957). Åvall (1957) totesi, että ne kukkakaalit, joista lehdet on poistettu, kärsivät pienimmät haihtumistappiot ja että tällaiset kukkakaalit olivat varsin alttiita mekaanisille vaurioille. Viikissä kukkakaali varastoitiin typistetyin suojuslehdin, ja niiden suojaava vaikutus näkyi selvästi. Jos kukinto kosketti varastoinnin aikana laatikon pohjaa, se tummui kosketuskohdastaan. Suojuslehtien kohdalla ei painaumia ollut.

Muovi ehkäisi tehokkaasti kukkakaalista tapahtuvaa haihduntaa. Neljä viikkoa kestäneen varastoinnin jälkeen haihtumistappio oli noin $1 \%$ ja kaikki kukinnot olivat kovia. Täten siis kukintojen pehmenemistä, joka ensinnä aiheutti kukkakaalin laadun heikkenemistä, voidaan muovin avulla rajoittaa. Sen sijaan pehmenemistä ei muovipakkauksessakaan kokonaan vältetty. Vuonna 1964 oli muoviin pakattujen kukkakaalien haihtumistappio 6 viikon varastoinnin jälkeen vain $1 \%$, mutta kymmenesosa kukinnoista oli pehmennyt. Käytännön kannalta tällä ei kuitenkaan ole merkitystä, sillä jo neljännen varastointiviikon aikana kukintojen pinta alkoi pilaantua, mikä siis muoviin pakatuissa erissä muodostui ensimmäiseksi 
kauppa-arvoa alentavaksi tekijäksi. Täten muoviin pakattua kukkakaalia voitiin säilyttää enintään kuukauden verran. Samaan tulokseen ovat eräät saksalaiset tutkijat päätyneet (BANHOLzer 1965, KARCH 1965). Pitemmistäkin säilymisajoista tosin löytyy kirjallisuudesta mainintoja, esimerkiksi 8 viikkoa (FrIEDRICH et al. 1963) ja jopa 3 kuukautta (ULRICH 1963). Näin huomattaviin säilyvyyseroihin saattaa eri lajikkeitten välisten erojen lisäksi olla syynä pakkaukseen käytetyn muovin laatu sekä reijitys. Huonosti kaasuja läpäisevässä ja niukasti reijitetyssä pakkauksessa muuttuu ilman koostumus säilytettävän tuotteen hengityksen takia siten, että hiilidioksidipitoisuus suurenee ja happipitoisuus pienenee. Jos happi pakkauksen sisältä loppuu, tuote turmeltuu. Sen sijaan on todettu, että esim. $10 \% \quad \mathrm{CO}_{2}, \quad 11 \% \mathrm{O}_{2}$ ja $79 \% \quad \mathrm{~N}_{2}$ sisältävässä kaasuseoksessa kukkakaali säilyy tavallista kauemmin (Sмгтн 1940). On myös huomioitava ns. subjektiivisten tekijöitten osuus verrattaessa eri tutkijoitten ilmoittamia kukkakaalin säilymisaikoja, sillä kaikissa tapauksissa arvostelu perustui osittain silmävaraisiin havaintoihin.

Edellä selostettujen tutkimusten perusteella voidaan $2-4$ viikkoa kestävää asianmukaisissa tiloissa tapahtuvaa kukkakaalin varastointia ehdottaa käytettäväksi yhtenä keinona pyrittäessä vakaaseen hintaan.

\section{Ti $i$ vis tel $m a ̈$}

Kukkakaalin (Flora Blanca) varastointia tutkittiin v. 1963-66. Tutkimusvarastossa oli ilman lämpötila $1-2^{\circ}$ ja suhteellinen kosteus $90-95 \%$.

Todettiin, että haihdunta ja kukinnon pehmeneminen ensinnä aiheuttivat kukkakaalin kauppa-arvon alenemista. Näistä syistä oli tutkitun kukkakaalilajikkeen säilyvyys noin $2-3$ viikkoa. Keskikokoiset $0.5-0.6 \mathrm{~kg}$ painavat kukinnot säilyivät parhaiten.

Muoviin pakattujen kukintojen haihtumistappio oli varsin pieni. Niiden laatu huononi ensinnä kukinnon pinnan vioittumisen takia, mistä syystä niitä voitiin säilyttää enintään kuukauden verran.

Pyrittäessä vakauttamaan kukkakaalin hintaa on lyhytaikainen varastointi huomionarvoinen keino.

\section{KIRJALLISUUS}

ApEland, J. 1958. Lagring av blomkâl, Rett. nr. 20 frå Institutt for grønsakdyrking. Norges landbr. högsk. $4 \mathrm{~s}$.

Banholzer, G. 1965. Ergebnisse zur Normallagerung von Blumenkohl im Anschluss an die späte Freilandernte. Deut. Gartenb. 12: $211-214$.

Brouwer, de W. \& Коот, van I. J. 1955. Bruinkleuring bij blomenkool na de oogst. Meded. dir. van de Tuinbouw 18: 846-855.

Friedrich, G. \& Karch, G. 1963. Die Bedeutung der Kühllagerung für die Verbesserung der Gemüseversorgung. Deut. Gartenb. 10: $299-301$.

Gröschner, P. 1963. Diskussionbeitrag zu: Die Einlagerung von Herbstblumenkohl. Ibid. 10:60.

Hruschкa, H. W. \& Kaufman, J. 1949. Storage tests with Long Island cauliflower to inhibt leaf abscission by using plant growth regulators. Proc. Amer. Soc. Hort. Sci. 54: 438-446.

KARch, G. 1965. Die zweckmässige verwendung von Polyäthylenfolie bei Kühllagerung von Blumenkohl. Deut. Gartenb. 12: 214-216. 
KaUfman, J. \& Ringel, S. M. 1961. Tests of growth regulators to retard yellowing and abscission of cauliflower. Proc. Amer. Soc. Hort. Sci. 78: 349-352.

KRUYK, P. A. 1957. Bewaring van blomenkool. Proefst. voor de groenten en fruittelt onder glas te Naaldwijk. Jaarsversl. 1956.

KURKI, L. 1966. Vihannesten kuluttajapakkausten säilytysolosuhteista. Maatal. ja Koetoim. 20: 111 116.

LeE, S-H. \& Carolus, R. L. 1949. Foliar abscission of stored cauliflower and cabbage. Mich. Sta. Coll. Techn. Bul. 216. 40 p.

PIEH, K. 1965. Kühlung von Obst und Gemüse. Deut. Gartenb.wirtsch. 13: 136-140.

Rose, D. H. \& Whiteman, T. M. 1949. The commercial storage of fruits, vegetables and florist's stocks. United States Dept. of Agr. Circular no. 278.

Sмrтн, W. H. 1940. The storage of broccoli and cauliflower. J. Pomol. and Hort. Sci. 18: $287-93$. Ulrich, H. 1963. Die Einlagerung von Herbstblumenkohl. Deut. Gartenb. 10: 102-103.

Voıpıo, I. 1966. Kaalin esikäsittely varastointia varten. Maatal. ja Koetoim. 20: 133-140. Åvalı, H. 1957. Konsumptionsförpackning av köksväxter. Medd. 102 Stat. trädg. förs. $46 \mathrm{~s}$. Vihanneksien, marjojen ja omenien lajittelu- ja pakkausohjeet 1963. Puutarhatuotteiden standardisoimistoimikunnan julkaisu. $36 \mathrm{~s}$. Helsinki.

S U M M A R Y :

STORAGE OF CAULIFLOWER

IRMA SUHONEN

Institute of Horticulture, University of Helsinki, Viik

The storage of cauliflower (variety Flora Blanca) was studied in $1963-66$. The cauliflower was grown on experimental fields at Viik (Table 1) and the curds were stored directly after harvesting. The main points were:

1) How long can cauliflower be stored if the storage temperature is $1-2^{\circ} \mathrm{C}$ and relative humidity $90-95 \%$.

2) How big are storage losses caused by evaporation in above circumstances.

3) What are the benefits from wrapping cauliflowers in PV-bags.

4) What changes in the appearance of curds occur during storage. The appearance was determined in the following ways. Flowers and leaves : $3=$ first class appearance, $0=$ destroyed. Frimness of heads: $100=$ all heads firm, $0=$ all heads soft.

The results (based on the weight of the cauliflower before storage) are given in Tables 2 to 4 . Accordingly, cauliflower Flora Blanca can be stored $2-3$ weeks and middle size curds $(0.6 \mathrm{~kg}) \mathrm{keep}$ best. Storage losses caused by evaporation varied in different weeks (Figure 1), during 4 weeks of storage they were about $14 \%$, while if the cauliflowers were wrapped in PV-bags, the losses were only about $1 \%$. The cauliflowers in PV-bags were firstly affected by spots on the flowers, without PV-bags there was wilting. The first spots (dead lesions) appeared during the fourth storage week. Thus cauliflowers in PV-bags could be stored without significant losses about 4 weeks. 